\title{
Histological Changes on Cervical Exfoliated Cells Following Administration of a Hormonal Contraception
}

\author{
Wala M Elfatih Mahgoub ${ }^{1 *}$, Ibrahim A Ali ${ }^{2}$, Khalid Mohamed ${ }^{1}$ and Kamal Elbadawi ${ }^{1}$ \\ ${ }^{1}$ Department of Anatomy, The National Ribat University, Sudan
}

${ }^{2}$ Department of Physiology, The National Ribat University, Sudan

Submission: April 27, 2018; Published: May 30, 2018

*Corresponding author: Wala Mohamed Elfatih Mahgoub AbdAlla, Department of Anatomy, Faculty of Medicine, The National Ribat University, Khartoum, Sudan; Email: walla_9@live.com

\begin{abstract}
Purpose: To determine the relationship between the usage of hormonal contraception and dysplastic changes in the cervical exfoliated cells.

Materials and Methods: This is an epidemiological retrospective cohort study conducted in obstetrics and gynecology clinics and Hospitals of Khartoum state. 60 women of different age groups were studied. The sample was divided into two groups, 39 of them were the exposed group i.e. the women who were using hormonal contraception, and 21 were the not-exposed group i.e. the women who had never used hormonal contraception. Pap stain was the method that used to detect the dysplastic changes in the cervical exfoliated cells.
\end{abstract}

Results: $10.3 \%$ of the exposed group showed increased nuclear/cytoplasmic ratio in comparison, no one of the not-exposed group showed this feature (Figure 1\&2); $59 \%$ of the exposed group showed active mitosis in comparison to $14.3 \%$ of the not-exposed group (Figure 3); $26 \%$ of the exposed group showed condensed chromatin status while all the not-exposed group had homogenous chromatin (Figure 4\&5); 18\% of the exposed group had irregular exfoliated cervical cells and all the not-exposed group had regular shapes of exfoliated cervical cells (Figure 6\&7), $21 \%$ of the exposed group showed variation on the shapes and sizes of exfoliated cervical cells (pleomoephism) while no one of the notexposed group showed this feature (Figure 8). This study found that, the women who used hormonal contraception were 4 times more likely to develop dysplastic changes in the cervical exfoliated cells than those who didn't ( $R R=4.1)$. The duration of hormonal contraception usage and the dysplastic changes in cervical exfoliated cells-in term of increased nuclear/cytoplasmic parameter-was statistically significant ( $\mathrm{p}<0.05)$.

Conclusion: Usage of hormonal contraception is linked to increase the possibility of developing dysplastic changes in the cervical exfoliated cells which in turn harboring the potentiality of developing cervical cancer. There is strong association between the duration of hormonal contraception usage and dysplastic changes in the cervical exfoliated cells. Results in this study correlate with previous studies done in America, U.K and others.

Keywords: Hormonal contraception; Dysplasia; Cervical intraepithelial lesion; Carcinoma in-situ; Nuclear/Cytoplasmic ratio; Active mitosis; Chromatin Status; Pleomorphism; Oral contraceptive pills; Reproductive lifespan; Gastrointestinal tract; Liver cirrhosis; Vaginal discharge; Cervical abnormalities; Minipills; Invasive cancer; Papanicolaou stain; Vaginal bleeding; Menopausal women; Pleomorphism; Cervical dysplastic lesions

Abbreviations: OCP: Oral Contraceptive Pills; CIN: Cervical Intra Epithelial Neoplasia; CIS: Carcinoma In Situ; RR: Risk Ratio

\section{Introduction}

Many women around the world have been using contraception, in one form or another, for thousands of years. Some use it for extremely long periods of time during their reproductive lifespan. There are different types of contraception that could be used by women at different stages in their lives and no one method suits everyone. There are different types of contraceptives such as; combined hormonal contraception, progesterone only preparations, intrauterine contraception and barrier methods [1]. The oral contraceptive pills (OCP)-“the pill"-contains a mixture of two hormones a synthetic estrogen and a synthetic form of progesterone. It is estimated that at least 200 million women worldwide have taken OCP since it was first marketed. The OCP affects almost all the systems in the body such as the nervous system in form of mood changes and headache, the gastrointestinal tract in form of nausea and liver cirrhosis, the breasts in form of breast pain, vascular system in form of venous thromboembolism and hypertension, reproductive system in form of vaginal discharge and cervical 


\section{Global Journal of Reproductive Medicine}

abnormalities [1,2]. Progestin-Only Pills, often called "minipills," inhibit ovulation in about 50 percent of women. Their primary mechanism of action is thickening of the cervical mucus. This effect occurs within hours of taking a progestin-only pill and peaks about four hours after the pill is taken [3]. The injectable contraceptives contain a progestin like the natural hormone progesterone in a woman and do not contain estrogen, and so can be used throughout breastfeeding and by women who cannot use methods with estrogen [4].

Subdermal implant (Implanon) is inserted subdermally under local anaesthetic into the upper arm. It releases the progestogenetonogestrel and lasts for three years and thereafter can be easily removed and another one could be inserted if requested [1]. The cervix is the lower cylindrical part of the uterus; its internal aspect which is closed to uterus lined with simple columnar epithelium and the external aspect that bulges into the lumen of the vagina is covered with stratified squamous epithelium [5]. Cervical intra epithelial neoplasia (CIN) also known as dysplasia, is defined as a spectrum of intraepithelial changes that begin as well differentiated intra epithelial neoplasm and classified as a mild dysplasia, and ends with invasive cancer. The neoplastic changes are confined to the squamous epithelium and include chromatin clumping (abnormal chromatin aggregates), loss of polarity (irregular shape of cells) with increase in the nuclear/ cytoplasmic ratio and the presence of abnormal mitoses (mitotic figures) [6]. CIN is graded from 1-3; the grading is based on the amount of undifferentiated cells present from the basement membrane to the surface epithelium. When up to one-third of this distance is involved the grade is CIN1, when more than onethird and up to two-thirds is involved the grade is CIN2, and when more than two-thirds are involved the grade is CIN3. When the patient has full thickness involvement from the basement membrane to the surface epithelium, this condition is referred to as carcinoma in situ (CIS). Although the current theory is that CIS is part of the spectrum of CIN. The presence of CIN 3 implies a greater risk for the development of invasive cancer than does the presence of CIN 1 or 2, it is only a relative risk. There are currently no objective markers of increased risk for invasion. These are desperately needed in order to plan interventions and assess their impact $[6,7]$. The purpose of the present study is to determine whether there is a relationship between the usage of hormonal contraception and the development of dysplastic changes in the cervical exfoliated cells.

\section{Materials and Methods}

An epidemiological retrospective cohort study was conducted in obstetrics and gynecology clinics and hospitals of Khartoum state. Sixty women (39 exposed and 21 not exposed), were included in the study aged from 21 to 40 years, a questioner eliciting information regarding age, duration of hormonal contraception usage, type of hormonal contraception used and number of children was filled by the researcher of this study. The sample was divided into two groups, 39 of them were the exposed group i.e. the women who used hormonal contraception, and 21 were the not-exposed group i.e. the women who had never used hormonal contraception. Papanicolaou stain was the method that used to detect the dysplastic changes in the cervical exfoliated cells. The exposed group divided into three sub-groups in concordance with the duration of hormonal contraception usage, 19 of them were using hormonal contraception for less than 1 year, 18 were using hormonal contraception for (1-5) years and 2 were using hormonal contraception for (6-10) years. Papanicolaou stain was done to the all participants of the study including the exposed and not-exposed groups. Subjects included in the study were women at child bearing age whether receiving or not receiving hormonal contraception. Subjects excluded were women with known cervical pathological conditions, active vaginal bleeding and extremes of age (adolescent girls and menopausal women). Cervical smears collected by (a sterile steal spatula), then samples fixed in ( $95 \%$ alcohol), stained by the conventional Papanicolaou stain and examined under light microscope using $(\mathrm{x} 10)$ and $(\mathrm{x} 40)$ lens powers.

\section{Data analysis}

Data was analyzed using SPSS version 24 software. Descriptive statistics, frequencies and the association between the duration of hormonal contraception usage and dysplastic changes in cervical exfoliated cells was determined by using bivariate test.

\section{Ethical approval}

Local ethics committee approval was obtained for this study. Smears were only taken after informed consent was taken. Privacy and confidentiality were secured.

\section{Results}

No one of the not-exposed group showed increased nuclear/ cytoplasmic ration i.e. the entire not-exposed group showed normal nuclear/cytoplasmic ratio (Table 1-5). No one of the notexposed group showed condensed chromatin status. No one of the not-exposed group showed irregular shape of cells, i.e. the entire not-exposed group maintained the polarity of the cervical exfoliated cells (Figure 1-4). No one of the not-exposed group showed variation in the size and shapes of cells (pleomorphism). Incidence density of dysplastic changes on the cervical exfoliated cells among the exposed group was 589/1000 per (person-time), while the incidence density of dysplastic changes on the cervical exfoliated cells among the not-exposed group was 142/1000 per (person-time). The Risk Ratio (RR) is 4.1. This means, the women who used hormonal contraception were 4 times more likely to develop dysplastic cervical lesions in comparison with those who didn't used hormonal contraception. The Sig. (2-tailed) was .000 which means that there is significance between the duration of hormonal contraception usage and dysplastic changes in term of increased nuclear/ cytoplasmic ratio i.e. ( $p$ value $<0.05$ ), and the relationship is positive $53.6 \%$, which means that as one variable goes up or down so will the other one (Table 6-8). 
Table 1: Shows nuclear/cytoplasmic ratio among exposed group.

\begin{tabular}{|c|c|c|}
\hline Nuclear / Cytoplasmic Ratio & Frequency & Percent \\
\hline Normal & 35 & $89.70 \%$ \\
\hline Increased & 4 & $10.30 \%$ \\
\hline Total & 39 & $100 \%$ \\
\hline
\end{tabular}

Table 2: Shows active mitosis among exposed group.

\begin{tabular}{|c|c|c|}
\hline Active Mitosis & Frequency & Percent \\
\hline Absent & 16 & $41.00 \%$ \\
\hline Present & 23 & $59.00 \%$ \\
\hline Total & 39 & $100 \%$ \\
\hline
\end{tabular}

Table 3: Shows active mitosis among not-exposed group.

\begin{tabular}{|c|c|c|}
\hline Active Mitosis & Frequency & Percent \\
\hline Absent & 18 & $85.70 \%$ \\
\hline Present & 3 & $14.30 \%$ \\
\hline Total & 21 & $100 \%$ \\
\hline
\end{tabular}

Table 4: Shows chromatin status among the exposed group.

\begin{tabular}{|c|c|c|}
\hline Chromatin Status & Frequency & Percent \\
\hline Homogenous & 29 & $74.40 \%$ \\
\hline Condense & 10 & $25.60 \%$ \\
\hline Total & 39 & $100 \%$ \\
\hline
\end{tabular}

Table 5: Shows shape of cells among the exposed group.

\begin{tabular}{|c|c|c|}
\hline Shape of Cells & Frequency & Percent \\
\hline Regular & 32 & $82.10 \%$ \\
\hline Irregular & 7 & $17.90 \%$ \\
\hline Total & 39 & $100 \%$ \\
\hline
\end{tabular}

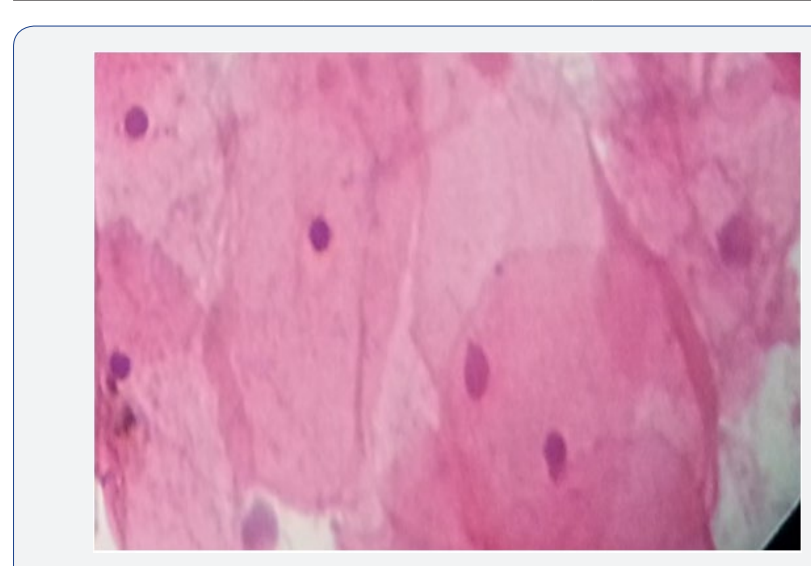

Figure 1: Light microscopic picture of cervical smear stained by using Pap stain, shows normal nuclear/cytoplasmic ratio. (Arrows show nuclei of cervical exfoliated cells, the line shows the borders of cervical exfoliated cell) (x40).

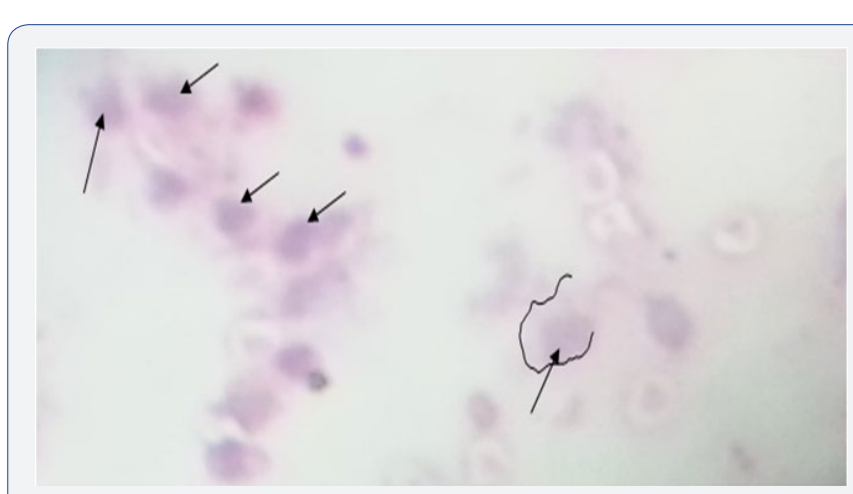

Figure 2: Light microscopic picture of cervical smear stained by using Pap stain, shows increased nuclear/cytoplasmic ratio. (Arrows show nuclei of cervical exfoliated cells, the line shows the borders of cervical exfoliated cell) (x40).

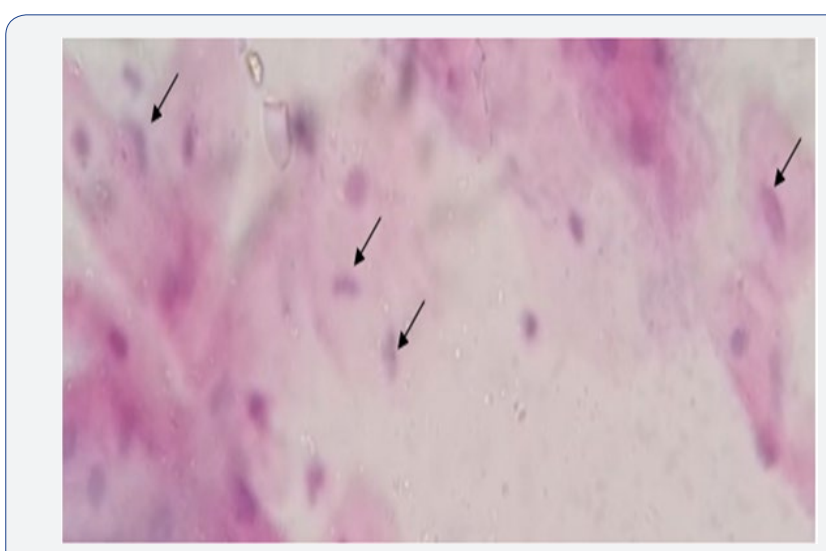

Figure 3: Light microscopic picture of cervical smear stained by using Papa stain, shows active mitosis. (Arrows show mitotic figures) (x40).

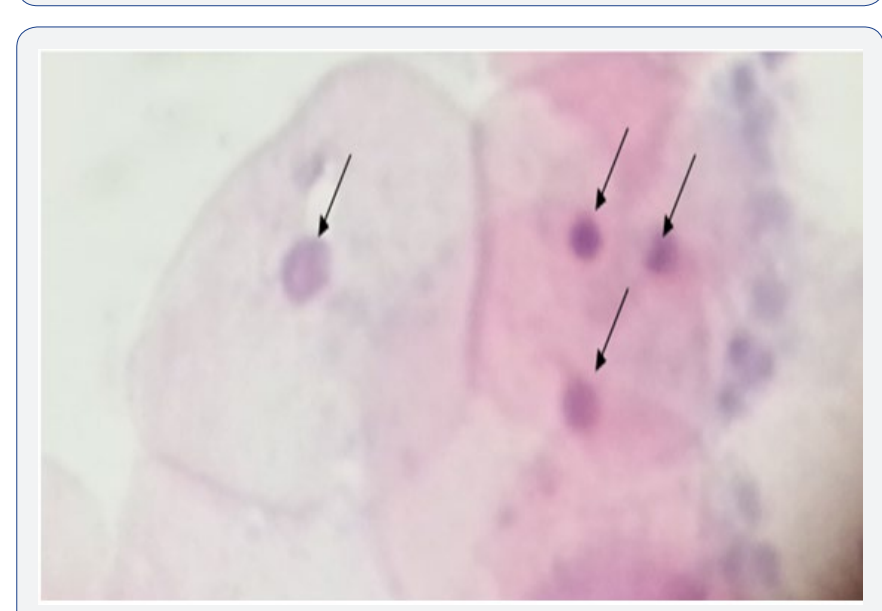

Figure 4: Light microscopic picture of cervical smear stained by using Pap stain, shows homogenous Chromatin Status. (Arrows show homogenous chromatin status) (x40).

Table 6: Shows pleomorphism among the exposed group.

\begin{tabular}{|c|c|c|}
\hline Pleomorphism & Frequency & Percent \\
\hline Present & 8 & $20.50 \%$ \\
\hline Absent & 31 & $79.50 \%$ \\
\hline Total & 39 & $100 \%$ \\
\hline
\end{tabular}


Table 7: Shows the relationship between hormonal contraception usage (exposure) and development of dysplastic cervical lesions (disease).

\begin{tabular}{|c|c|c|c|}
\hline Groups & Diseased & Not-diseased & Total \\
\hline Exposed & 23 & 16 & 39 \\
\hline Not-exposed & 3 & 18 & 21 \\
\hline
\end{tabular}

Table 8: Shows the association between the duration of hormonal contraception usage and dysplastic changes in term of increased nuclear / cytoplasmic ratio.

\begin{tabular}{|c|c|c|c|}
\hline \multicolumn{2}{|c|}{$\begin{array}{l}\text { Association between usage } \\
\text { of hormonal contraception } \\
\text { and increased nuclearl } \\
\text { cytoplasmic ratio }\end{array}$} & \multirow{2}{*}{$\begin{array}{c}\begin{array}{c}\text { Duration of } \\
\text { hormonal }\end{array} \\
\text { contraception } \\
\text { usage }\end{array}$} & \multirow{2}{*}{$\begin{array}{c}\begin{array}{c}\text { Nuclearl } \\
\text { cytoplasmic } \\
\text { ratio }\end{array} \\
.536^{\star *}\end{array}$} \\
\hline $\begin{array}{l}\text { Duration of } \\
\text { Hormonal }\end{array}$ & $\begin{array}{c}\text { Pearson } \\
\text { Correlation }\end{array}$ & & \\
\hline Contraception & Sig. (2-tailed) & & 0 \\
\hline Usage & $\mathrm{N}$ & 39 & 39 \\
\hline \multirow{3}{*}{$\begin{array}{c}\text { Nuclear/ } \\
\text { cytoplasmic } \\
\text { ratio }\end{array}$} & $\begin{array}{l}\text { Pearson } \\
\text { Correlation }\end{array}$ & $.536^{\star *}$ & 1 \\
\hline & Sig. (2-tailed) & 0 & \\
\hline & $\mathrm{N}$ & 39 & 39 \\
\hline
\end{tabular}

Discussion

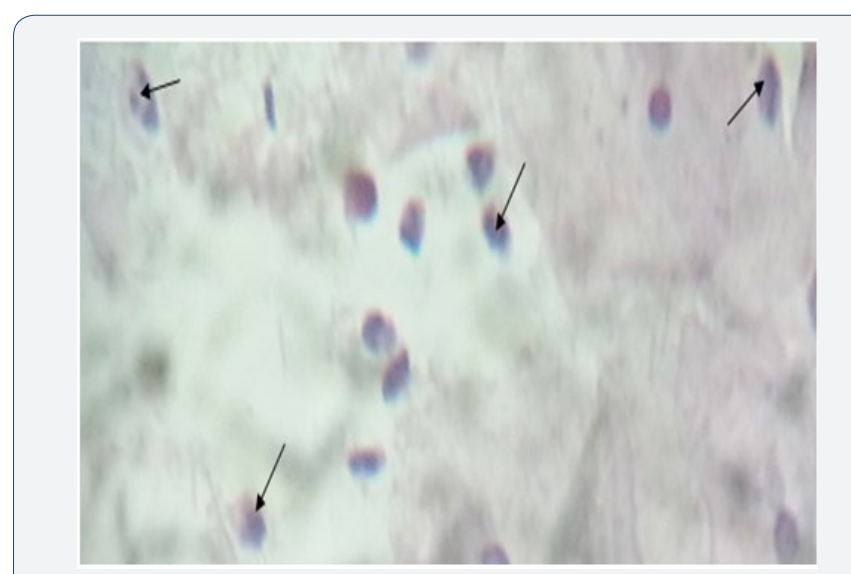

Figure 5: Light microscopic picture of cervical smear stained by using Papa stain, shows condensed chromatin status. (Arrows show condensed chromatin) (x40).

The estimation of the relationship between using hormonal contraception and developing cervical dysplastic changes in this study was determined to be 4 times in the women who used hormonal contraception in comparison with those who didn't $(\mathrm{RR}=4.1)$; this finding is close to a finding in a retrospective epidemiological study done by Bryan P Negrini, et al. [2] in Washington D.C searched the effect of OCP on cervical mucosa by using Papanucloua stain; they concluded that, women who had used OCP were about three times more likely to have high grade SIL (RR=3.2) (Figure $5 \& 6$ ). Another study done by Appleby P, et al. [8] as part of the international collaboration of epidemiological studies of cervical cancer in 2007; that study linked the recent long term users of OCP to develop not only dysplastic cervical lesions but also the possibility of developing invasive cervical cancer and stating that among current users of oral contraceptives the risk of invasive cervical cancer increased with increasing duration of use (RR for 5 or more years' use versus never use, 1.90). Approximately similar findings approved in another study done by Brinton L, et al. [9] in Entebbe, Uganda, in September 2013 which concluded, the recent long terms users of $(\mathrm{COC})$ at high risk of developing invasive cervical carcinoma with $\mathrm{RR}=1.7$.

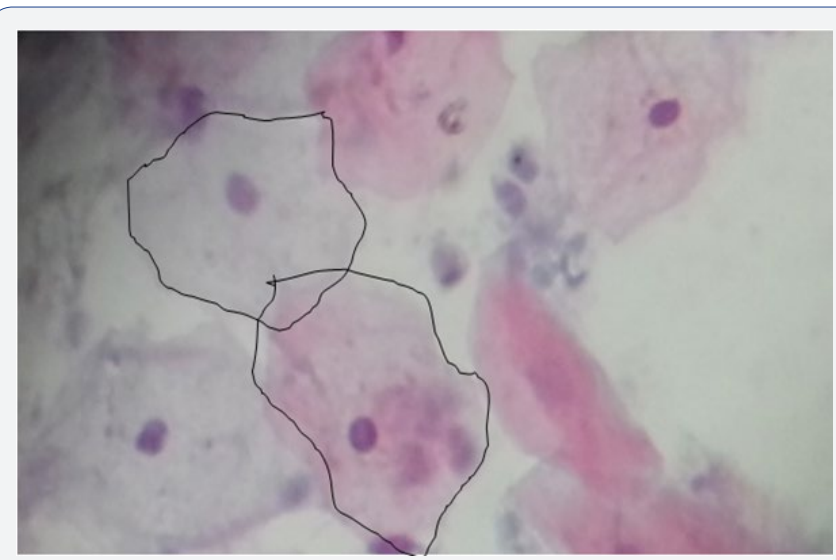

Figure 6: Light microscopic picture of cervical smear stained by using Pap stain, shows regular shape of cervical cells. (Lines show borders of exfoliated cervical cells) (x40).

This study completely agreed with a prospective cohort study which followed 47000 women since 1968 and done by Beral V, et al. [10], in the Royal college of general practioners, that study stated, those who used OCP had a significant higher incidence rate of cervical cancer than never-users and the standardized incidence rate for cervical cancer in women who had taken the pill for more than 10 years was 4 times than in never-users. This study reached a conclusion that there is a strong correlation between the duration of hormonal contraception usage and the dysplastic changes in the cervical epithelial cells in the term of increased nuclear/ cytoplasmic ratio (Table 8) and (Figure 2) this finding agreed with a case-control study done by Brinton L, et al. [9] on 759 invasive cervical cancer patients and 1430 controls in Panama, Costa Rica, Colombia and Mexico that study concluded that, the recent long-term users for more than 5 years were at highest risk; and also agreed with a study done by Sabatini R, et al. [11] in Germany on the adverse effect of OCP, classifying the adverse effect of OCP into three classes; class one including the mild adverse effects, class two including the moderate adverse effects and class three including the sever adverse effects. Under the umbrella of the severe adverse effect was the possibility of developing cancers. The cancers that might be developed according to that study are cervical, ovarian, breast, endometrial, colorectal, skin, liver, pancreatic and neurofibromas growth. Under the title of cervical cancer that study stated that, the longer the duration of OCP the higher the possibility of developing cervical cancer. When cervical smear was taken in this study, it had been noticed presence of cervical ulcer and consequently bloody stained smears on two women who had 


\section{Global Journal of Reproductive Medicine}

been using sub-dermal implants and complained of bleeding irregularity, this observation agrees with a study done by Diaz J, et al. [12] in Brazil which stated that of almost 500 women who used levonorgestrel implants noted to have bleeding side effects (Figure 7 \& 8).

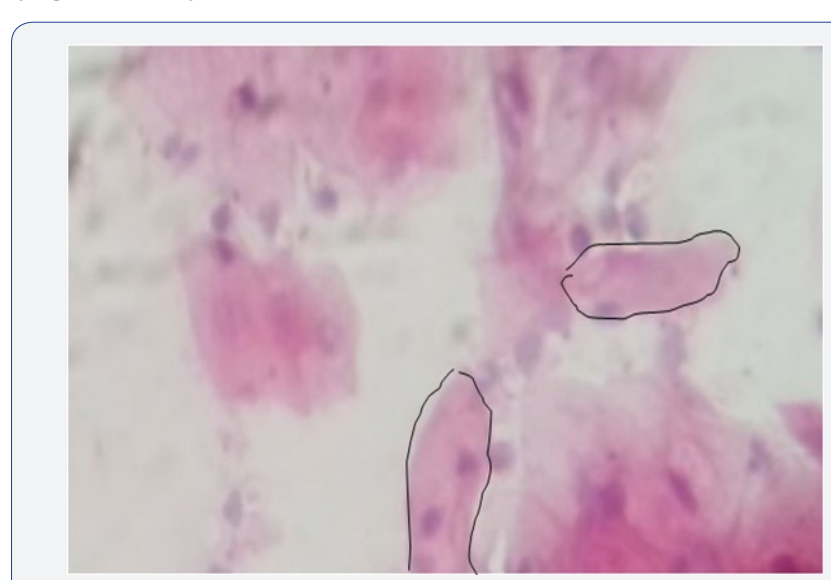

Figure 7: Light microscopic picture of cervical smear stained by using Pap stain, shows irregular shape of cervical cells. (Lines show borders of exfoliated cervical cells) $(\times 40)$.

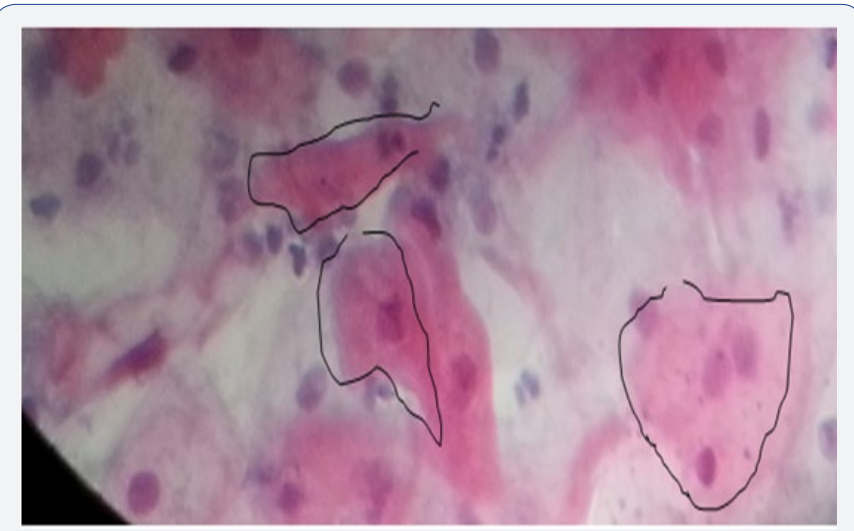

Figure 8: Light microscopic picture of cervical smear stained by using Pap stain, shows pleomorphism (variation in the shape and size of cells). (Lines show borders of exfoliated cervical cells) $(x 40)$.

\section{Conclusion}

This study found that, usage of hormonal contraception is linked to increase the possibility of developing dysplasia in cervical exfoliated cells and the women who used hormonal contraception are 4 times more likely to develop these lesions in comparison with those who didn't, cervical dysplastic changes in turn harboring the potentiality of developing invasive cervical cancer. The association between the duration of hormonal contraception usage and dysplastic changes in the cervical exfoliated cells was found to be statistically significant and with positive correlation which indicates; the longer the duration of hormonal contraception usage the more likely to develop cervical dysplastic lesions.

\section{References}

1 Susan Bewley, Ying Cheong (2011) Fertility control, contraception and abortion. In: Ash Monga and Stephen Dobbs. (Eds). Gynaecology. London: Hodder Arnold, UK, Pp. 62-70.

2 Negrini BP, Schiffman MH, Kurman RJ, Barnes W, Lannom L, et al (1990) Oral contraceptive use, human papilloma virus infection, and risk of early cytological abnormalities of the cervix. Cancer Res 50(15): 4670-4675.

3 PillsCO (2002) Abnormal uterine bleeding associated with hormonal contraception. Am Fam Physician 65(10): 2073-2081.

4 World Health Organization (2011) Family Planning: a global Handbook for providers. Update: evidence- based guidance developed through worldwide collaboration. Geneva, Switzerland.

5 Luiz Carlos Junqueira, Josf Caeneiro (2005) Female genital histology. In: Junqueira (Eds). Basic histology. New York: McGraw-Hill Medical, USA Pp. 20.

6 Ferenczy A, Winkler B (1987) Cervical intraepithelial neoplasia and condyboma. In: Kurman R (Eds) Blaustein's Pathology of the Female Genital Tract, New York: Springer-Verlag, USA Pp 184-191.

7 Boone C, Kelboff G, Steele V (1992) The natural history of intraepithelial neoplasia in humans with implications for cancer chemoprevention strategy. Cancer Res 52(7): 1651-1659.

8 Appleby P, Beral V, Colin D, Franceschi S, Goodhill A, et al. (20017) International Collaboration of Epidemiological Studies of Cervical Cancer. Cervical cancer and hormonal contraceptives. Lancet 370: 1609-1621.

9 Louise A Brinton, William C Reeves, Maria M Brenes, Rolando Herrero, Eduardo Gaitan, et al. (1990) Oral contraceptive use and risk of invasive cervical cancer. International Journal of Epidemiology. 19(1): 4-11.

10 Beral V, Hannaford P, Kay C (1998) Oral contraceptive use and malignancies of the genital tract. Royal College of general practioners. Lancet 2(8624): 1331-1335.

11 Sabatini R, Cagiano, et al. (2001) Adverse Effects of Hormonal Contraception. Journal Fur Reprodukionsmedizin and Endokrinologie. Journal of Reproductive Medicine and Endocrinology 8(1): 130-156.

12 Diaz J, Faundes A, Olmos P, Diaz M (1996) Bleeding complaints during the first year of Norplant implants use and their impact on removal rate. Contraception 53(2): 91-5. 

(C) (1) Tommons Attribution 4.0 License

DOI: 10.19080/GJORM.2018.04.555646

\section{Your next submission with Juniper Publishers} will reach you the below assets

- Quality Editorial service

- Swift Peer Review

- Reprints availability

- E-prints Service

- Manuscript Podcast for convenient understanding

- Global attainment for your research

- Manuscript accessibility in different formats ( Pdf, E-pub, Full Text, Audio)

- Unceasing customer service

Track the below URL for one-step submission https://juniperpublishers.com/online-submission.php 